\title{
antibiotics
}

ISSN 2079-6382

www.mdpi.com/journal/antibiotics

Review

\section{Old and New Glycopeptide Antibiotics: Action and Resistance}

\section{Elisa Binda ${ }^{1,2, *}$, Flavia Marinelli ${ }^{1,2}$ and Giorgia Letizia Marcone ${ }^{1,2}$}

1 Department of Biotechnology and Life Sciences, University of Insubria, Varese 20100, Italy; E-Mails: flavia.marinelli@uninsubria.it (F.M.); giorgia.marcone@uninsubria.it (G.L.M.)

2 The Protein Factory, Interuniversity Centre Politecnico di Milano, ICRM CNR Milano and University of Insubria, Milan 21100, Italy

* Author to whom correspondence should be addressed; E-Mail: elisa.binda@uninsubria.it; Tel.: +39-0332-421-547; Fax: +39-0332-421-500.

External Editor: Dr. Sergei Vakulenko

Received: 28 July 2014; in revised form: 20 October 2014 / Accepted: 23 October 2014 /

Published: 4 November 2014

\begin{abstract}
Glycopeptides are considered antibiotics of last resort for the treatment of life-threatening infections caused by relevant Gram-positive human pathogens, such as Staphylococcus aureus, Enterococcus spp. and Clostridium difficile. The emergence of glycopeptide-resistant clinical isolates, first among enterococci and then in staphylococci, has prompted research for second generation glycopeptides and a flurry of activity aimed at understanding resistance mechanisms and their evolution. Glycopeptides are glycosylated non-ribosomal peptides produced by a diverse group of soil actinomycetes. They target Gram-positive bacteria by binding to the acyl-D-alanyl-D-alanine (D-Ala-D-Ala) terminus of the growing peptidoglycan on the outer surface of the cytoplasmatic membrane. Glycopeptide-resistant organisms avoid such a fate by replacing the D-Ala-D-Ala terminus with D-alanyl-D-lactate (D-Ala-D-Lac) or D-alanyl-D-serine (D-Ala-D-Ser), thus markedly reducing antibiotic affinity for the cellular target. Resistance has manifested itself in enterococci and staphylococci largely through the expression of genes (named van) encoding proteins that reprogram cell wall biosynthesis and, thus, evade the action of the antibiotic. These resistance mechanisms were most likely co-opted from the glycopeptide producing actinomycetes, which use them to avoid suicide during antibiotic production, rather than being orchestrated by pathogen bacteria upon continued treatment. van-like gene clusters, similar to those described in enterococci, were in fact identified in many glycopeptideproducing actinomycetes, such as Actinoplanes teichomyceticus, which produces teicoplanin,
\end{abstract}


and Streptomyces toyocaensis, which produces the A47934 glycopeptide. In this paper, we describe the natural and semi-synthetic glycopeptide antibiotics currently used as last resort drugs for Gram-positive infections and compare the van gene-based strategies of glycopeptide resistance among the pathogens and the producing actinomycetes. Particular attention is given to the strategy of immunity recently described in Nonomuraea sp. ATCC 39727. Nonomuraea sp. ATCC 39727 is the producer of A40926, which is the natural precursor of the second generation semi-synthetic glycopeptide dalbavancin, very recently approved for acute bacterial skin and skin structure infections. A thorough understanding of glycopeptide immunity in this producing microorganism may be particularly relevant to predict and eventually control the evolution of resistance that might arise following introduction of dalbavancin and other second generation glycopeptides into clinics.

Keywords: glycopeptides; resistance; van genes; Nonomuraea sp. ATCC 39727; dalbavancin

\section{Natural Glycopeptide Antibiotics}

Glycopeptide antibiotics (GPAs) are frequently used to treat life-threatening infections caused by multidrug-resistant Gram-positive pathogens, such as Staphylococcus aureus, Enterococcus spp. and Clostridium difficile. They are drugs of last resort against methicillin-resistant Staphylococcus aureus (MRSA), which is nowadays a major cause of community-acquired infections and results in high morbidity and mortality rates in hospital-acquired infections [1]. First-generation GPAs are natural products composed of glycosylated non-ribosomal heptapeptides produced by a diverse group of actinomycetes $[2,3]$.

The common structural motif is a core heptapeptide scaffold containing aromatic amino acids that have undergone extensive oxidative cross-linking and decoration with different moieties, such as sugar residues, chlorine atoms and lipid chains. Vancomycin and teicoplanin (Figure 1) represent the first generation of clinically important GPAs. Vancomycin, produced by the actinomycete Amycolatopsis orientalis, was first introduced in clinics in 1958, whereas teicoplanin, produced by Actinoplanes teichomyceticus, was first reported in 1978 and then introduced in clinical use in Europe in 1988 and in Japan in 1998 [1,4]. These two main antimicrobial GPA scaffolds (Figure 1) contain proteinogenic (Tyr, Leu, Asn, Ala and Glu) and non-proteinogenic amino acids (4-hydroxyphenylglycine, 3,5-dihydroxyphenylglycine and $\beta$-hydroxytyrosine). Five of the seven residues in vancomycin are aromatic, and two are aliphatic, while all seven are aromatic in teicoplanin [5]. Consequently, the number of oxidative cross-links between aromatic amino acids are three in vancomycin and four in teicoplanin, conferring the peculiar structural conformation representing the binding pocket for the cellular antibiotic target [6]. 
Figure 1. Structures of natural and semi-synthetic glycopeptide antibiotics (GPAs). Vancomycin and teicoplanin are natural products. In the case of teicoplanin, the clinically used antibiotic is a mixture of five lipoglycopeptide molecules differing in the length (C10-C11) and branching of the fatty acid tail, whose main component, the one reported in the figure, bears the 8-methylnonanoic (iso-C10:0) acid and is named T-A 2 -2. Oritavancin and telavancin are semi-synthetic second generation GPAs belonging to the vancomycin family. Dalbavancin is the semi-synthetic derivative of the teicoplanin-like A40926.
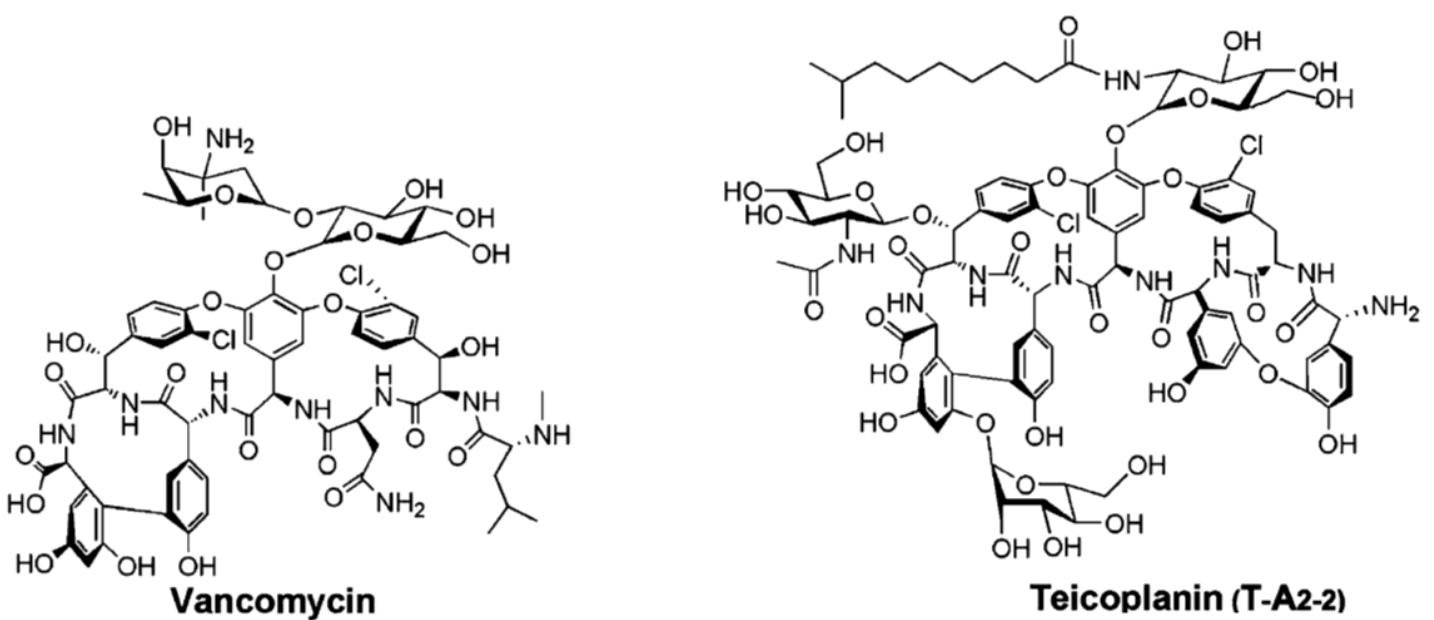

Teicoplanin (T-A2-2)

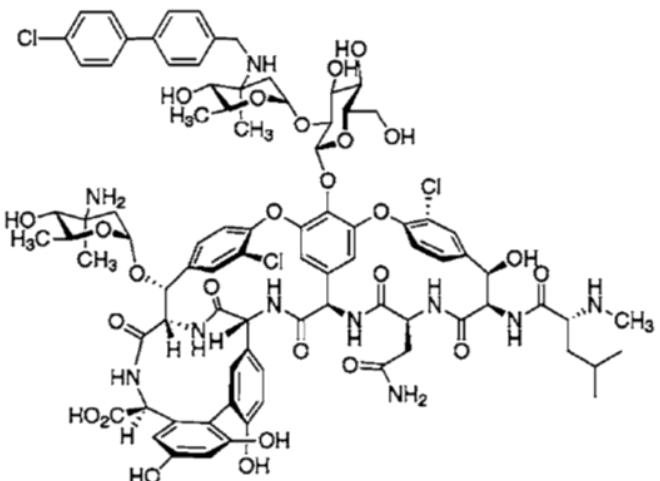

Oritavancin

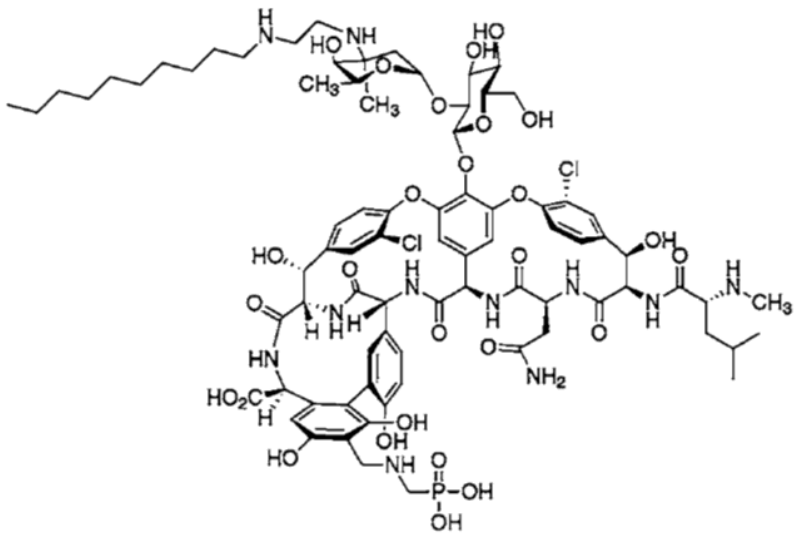

Telavancin

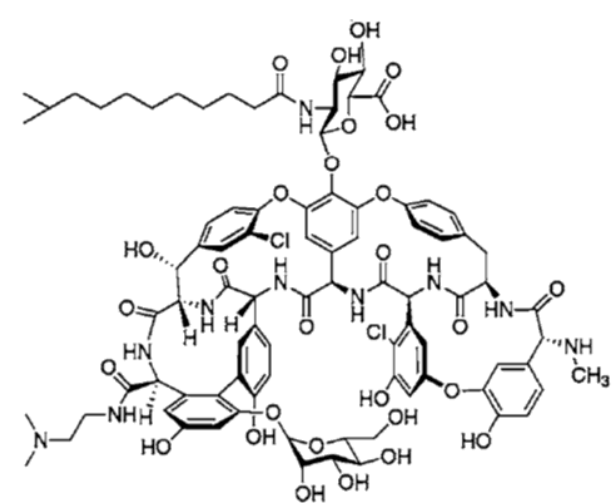

Dalbavancin 
Many more GPAs with amino acid sequences that differ from teicoplanin and vancomycin exist in nature and continue to be discovered by natural product screening (for an extensive review, see [2,7]). The diverse heptapeptide scaffolds undergo further biosynthetic modifications that include glycosylation, halogenation, methylation and, in some cases, sulfation and sugar acylation. Tailoring of GPAs can alter their chemical and biological properties by increasing solubility, imparting stability, affecting dimerization, determining membrane attachment, limiting conformational flexibility, avoiding degradation and evading resistance [7-9]. New GPA scaffolds and related tailoring enzymes have been recently found by screening environmental DNA libraries by metagenomics [10-12].

Vancomycin and teicoplanin (Figure 1) contain two chlorine atoms and are glycosylated by a disaccharide on amino acid residue 4 in vancomycin or by three monosaccharides at residues 4, 6 and 7 in teicoplanin. The glucosamine moiety attached to residue 4 in teicoplanin is acylated by a fatty acid chain. Clinically used teicoplanin is a mixture of five lipoglycopeptide molecules differing in the length (C10-C11) and branching of the fatty acid tail, whose main component is the one bearing the 8-methylnonanoic (iso-C10:0) acid and named T-A2-2 [13,14].

GPAs inhibit bacterial cell wall synthesis by binding to the D-Ala-D-Ala dipeptide terminus of the peptidoglycan (PG) precursors, sequestering the substrate from transpeptidation and transglycosylation reactions in the late extracellular stages of PG cross-linking. The D-Ala-D-Ala complex with GPAs is stabilized by an array of hydrophobic van der Waals contacts and five hydrogen bonds lining the antibiotic binding pocket $[6,15]$. Cross-linked PG is needed for the appropriate tensile strength of the cell wall. Thus, GPAs action ultimately results in destabilizing the cell wall integrity, with bacterial cell death occurring presumably due to osmotic insult. The requirement for direct access of GPAs to the target PG precursor explains the selective inhibition of Gram-positive bacteria. Gram-positive bacteria expose PG precursors on the external surface of the cytoplasmic membrane, whereas Gram-negative bacteria are protected by the presence of an outer lipopolysaccharide membrane impermeable to large biomolecules [3].

The antibacterial spectrum of teicoplanin activity against Gram-positive bacteria is similar to that of vancomycin, but teicoplanin shows an increased potency, particularly against some clinical isolates belonging to Staphylococcus, Streptococcus and Enterococcus genera [16,17]. Acylation of teicoplanin confers a lipophilic nature to the antibiotic that is suggested to impart superior antimicrobial activity and pharmacokinetics in comparison to vancomycin [3,18-20]. Consequently, most of the second generation semi-synthetic GPAs were prepared introducing hydrophobic moieties in the heptapeptide scaffold in order to confer increased membrane anchoring ability, leading to improved drugs [6,20,21].

\section{Semi-Synthetic Glycopeptide Antibiotics}

The spread of resistance to vancomycin in enterococci since 1988 and the emergence of high-level GPA resistance in clinical isolates of MRSA since 2002 have prompted the search for second generation drugs belonging to the GPA class. Second generation GPAs are semi-synthetic derivatives of natural products.

Telavancin (Vibativ) (Figure 1, Table 1), firstly approved by the Food and Drug Administration (FDA) for clinical use in 2009, is a derivative of vancomycin and differs from the parent compound by the addition of a hydrophobic and a hydrophilic group to the vancomycin structure. The length of the 
hydrophobic side chain was chosen to reach a compromise between optimized activity against MRSA (8-10 C) and vancomycin resistant enterococci (VRE) (12-16 C). The hydrophilic properties of the phosphonate group improve the adsorption, distribution, metabolism and excretion profile of the compound. Pharmacological studies suggest that the enhanced activity of telavancin versus vancomycin on Streptococcus pneumoniae, Staphylococcus aureus (to a lesser extent) and enterococci (including VRE) results from a complex mechanism of action, which involves perturbation of lipid synthesis and, possibly, membrane disruption $[16,21,22]$.

Table 1. Second generation GPAs approved and/or in development [23].

\begin{tabular}{|c|c|c|c|c|}
\hline Drug & GPA Precursor & Microbiological Spectrum & $\begin{array}{l}\text { Main Clinical } \\
\text { Indication }\end{array}$ & Status \\
\hline $\begin{array}{l}\text { Oritavancin } \\
\text { (Orbactiv) }\end{array}$ & Chloroeremomycin & $\mathrm{MRSA}^{1}, \mathrm{VRSA}^{1}, \mathrm{VRE}^{1}$ & $\mathrm{ABSSSI}^{2}$ & $\begin{array}{l}\text { approved by } \\
\text { FDA }^{3} \text { in } 2014\end{array}$ \\
\hline \multirow{2}{*}{$\begin{array}{l}\text { Telavancin } \\
\text { (Vibativ) }\end{array}$} & \multirow{2}{*}{ Vancomycin } & $\begin{array}{c}\mathrm{MRSA}^{1}, \mathrm{MSSA}^{1}, \mathrm{VSE}^{1}, \\
\text { Streptococcus pyogenes }\end{array}$ & $\mathrm{cSSSI}^{2}$ & $\begin{array}{l}\text { approved by } \\
\text { FDA }^{3} \text { in } 2009\end{array}$ \\
\hline & & Staphylococcus aureus & HABP/VABP ${ }^{2}$ & $\begin{array}{l}\text { approved by } \\
\text { FDA }^{3} \text { in } 2013\end{array}$ \\
\hline $\begin{array}{l}\text { Dalbavancin } \\
\text { (Dalvance) }\end{array}$ & A40926 & $\begin{array}{c}\text { MRSA }^{1}, \text { MSSA }^{1}, \\
\text { Streptococcus pyogenes }\end{array}$ & $\mathrm{ABSSSI}^{2}$ & $\begin{array}{l}\text { approved by } \\
\text { FDA }^{3} \text { in } 2014\end{array}$ \\
\hline
\end{tabular}

${ }^{1}$ MRSA, methicillin-resistant Staphylococcus aureus; VRSA, vancomycin-resistant Staphylococcus aureus; VRE, vancomycin-resistant enterococci; MSSA, methicillin-susceptible Staphylococcus aureus; VSE, vancomycin-susceptible enterococci; ${ }^{2}$ ABSSSI, acute bacterial skin and skin structure infections; cSSSI, complicated skin and skin structure infections; HABP/VABP, hospital-acquired and ventilator-associated bacterial pneumonia; ${ }^{3}$ FDA, Food and Drug Administration.

Oritavancin (Orbactiv) (Figure 1, Table 1) is the $N$-alkyl-p-chlorophenyl-benzyl derivative of chloroeremomycin produced by the actinomycete Amycolatopsis orientalis. Chloroeremomycin differs from vancomycin by the glycosylation pattern on amino acid residues 4 and 6. Although oritavancin presents a general spectrum of activity comparable to that of vancomycin, it offers considerable advantages in terms of intrinsic activity (especially against streptococci) and remains insensitive to the resistance mechanisms developed by staphylococci and enterococci; it is also active against Clostridium difficile [24]. The FDA recently accepted oritavancin for clinical use (Table 1). According to recent investigations on the mode of action, the biaryl group is involved in causing cell membrane depolarization. The superior activity against Gram-positive pathogens, including those resistant to vancomycin, is due to this dual-action mechanism, either inhibiting cell wall biosynthesis or affecting membrane integrity [25].

Dalbavancin (Figure 1, Table 1) is a semi-synthetic derivative of the teicoplanin-like molecule A40926, which was isolated from the actinomycete Nonomuraea sp. ATCC 39727 collected from an Indian soil in the mid-1980s [26]. In comparison with teicoplanin, A40926 lacks the saccharide moiety on the amino acid residue 6. It also differs from teicoplanin due to the presence of an acylaminoglucuronic acid on amino acid 4 instead of the acylglucosamine. Other structural differences between A40926 and teicoplanin include the terminal methylamino group, the position of one chlorine atom and the length of the fatty acid chain [27]. A40926 was used as a scaffold for an extensive program of chemical derivatization producing several clinical leads [27]; dalbavancin is the dimethylaminopropyl 
amide derivative (Figure 1) [5,28]. Dalbavancin shows an increased in vitro activity, compared to vancomycin, towards most Gram-positive pathogen bacteria, as well as an extremely long half-life, permitting once-weekly intravenous dosing [21,29]. On May 23 2014, clinical used dalbavancin (Dalvance) was approved by the FDA (Table 1).

The success of these three second generation GPAs as drug candidates and their potentiated antibacterial activities in comparison to vancomycin are stimulating further efforts in studying the mechanism of action/resistance and developing novel derivatives [20,30]. Due to the progresses achieved by total synthesis of GPAs by the group of Boger since 1999, single atom changes in vancomycin are today possible and pave the way to rationally redesign GPAs exhibiting potent antibacterial activity against VRE and MRSA [6]. The novel tailoring enzymes discovered by the group of Brady in environmental libraries offer a successful strategy for generating libraries of GPA variants [10-12].

\section{The van Gene Clusters in Pathogens}

Resistance to GPAs has manifested itself largely in enterococci through the expression of genes (named van) encoding proteins that reprogram cell wall biosynthesis and, thus, evade the action of the antibiotics. The onset of vancomycin resistance was long-delayed in comparison to all other antibiotics. The first case of vancomycin resistance was reported in Enterococcus faecium [31], but since that time, VRE have become increasingly widespread throughout the world and are nowadays found as multi-resistant opportunistic pathogens in hospitals and also in the environment (food animals) [1,32]. The detailed mechanism of van gene-mediated GPA resistance in enterococci was elucidated by Courvalin, Walsh and their co-workers in the 1990s (for an extensive review, see $[3,33]$ ). In the two most prominent manifestations of resistance (VanA and VanB phenotypes, Table 2), the PG precursor is remodeled to the terminal D-Ala-D-Lac, incorporating an ester linkage in place of the amide of D-Ala-D-Ala. The replacement of a dipeptide with a depsipeptide removes one of the hydrogen bonding interactions and leads to lone pair-lone pair repulsion, reducing by 1000-fold the affinity of GPAs to their molecular target and resulting in a corresponding 1000-fold loss in antimicrobial activity [34,35].

VanA-type resistance is characterized by high-level inducible resistance to both vancomycin and teicoplanin (Table 2) and is mediated by transposable elements, such as Tn1546 [36]. Tn1546 carries three genes encoding essential enzymes VanH, VanA, and VanX that remodel the PG precursor from D-Ala-D-Ala to D-Ala-D-Lac (Figure 2). VanH is a dehydrogenase that converts pyruvate into D-lactate [37]; VanA is a D-Ala-D-Lac ligase [34]; and VanX is a D-Ala-D-Ala dipeptidase that cleaves any residual D-Ala-D-Ala dipeptide [38,39], ensuring that PG precursors terminate mostly in D-Ala-D-Lac. Tn1546 also encodes two accessory proteins, VanY and VanZ, that are not required for, but contribute to, high-level resistance to vancomycin and teicoplanin, respectively [36]. VanZ confers low-level teicoplanin resistance in the absence of the other resistance proteins by an unknown mechanism [40]. VanY is a D,D-carboxypeptidase that hydrolyses the D-Ala C-terminal residue of PG precursors synthesized by using the D-Ala-D-Ala dipeptides that have escaped VanX hydrolysis [36,41].

The vanA operon expression is regulated by two genes, vanR and vanS, located upstream from vanH (Figure 2), that form a two-component signaling cascade [42-45]. Initiated by a ligand-induced dimerization of a cell surface His-kinase (VanS), it activates the signaling transcription factor VanR by phosphorylation and dimerization. In turn, the activated VanR binds to DNA and induces the expression 
of van genes [46]. The species responsible for inducing VanS dimerization and activation has been the subject of intense study: direct binding of the GPAs to VanS or its activation by cell wall intermediates that accumulate as a result of antibiotic action is still debated $[44,47,48]$. Despite the van $A$ and vanB operons having similar genetic organization and $c a$. 60\% sequence identity in VanHAX proteins, the sequences of the sensor kinases and response regulators of VanA and VanB-type strains are only 23\% and $34 \%$ identical at the amino acid level. The sensor kinase of VanB-type enterococci, named $\mathrm{VanS}_{\mathrm{B}}$, responds to different signals in comparison to VanS [49], being activated by vancomycin, but not by teicoplanin. In fact, vancomycin and teicoplanin induce resistance in VanA enterococci, whereas VanB strains sense vancomycin, but are resistant to teicoplanin (Table 2).

GPA resistance in enterococci can also results from substitution of the terminal D-Ala-D-Ala with D-Ala-D-Ser. The substitution leads only to a moderate (six-fold) decrease in the affinity of vancomycin for its target and accordingly to low-level resistance to the antibiotic [50]. Isolates of E. gallinarum, E. casseliflavus and E. flavescens (VanC phenotype) are intrinsically resistant to low levels of vancomycin, due to their constitutive production of $\mathrm{PG}$ precursors ending in D-Ala-D-Ser, but they remain sensitive to teicoplanin (Table 2). Three enzymes are required for the synthesis of D-Ala-D-Ser ending PG precursors: a racemase (VanT) that converts L-Ser to D-Ser, a ligase (VanC) that synthesizes D-Ala-D-Ser and a bi-functional D,D-dipeptidase/D,D-carboxypeptidase (VanXY $\mathrm{C}_{\mathrm{C}}$ ) that removes the D-Ala-D-Ala synthesized by the host ligase and removes the C-terminal D-Ala residue from the natural PG precursors [51]. Differently from VanX (D-Ala-D-Ala peptidase) and VanY (D,D-carboxypeptidase), VanXYC hydrolyzes both di- and penta-peptide. The genes encoding a two-component sensor $\left(\mathrm{VanS}_{\mathrm{C}}\right)$ and regulatory $\left(V_{a n R_{C}}\right)$ system are located downstream from the operon encoding VanC, VanXY $\mathrm{C}_{\mathrm{C}}$ and $V_{\text {anT }}$. The basis of the constitutive phenotype is due to mutations in the sensor $\operatorname{VanS}_{\mathrm{c}}$ [51-53].

More recently, other types of van operon structures (vanD, vanE, vanG, vanL, vanM, vanN) and corresponding resistance phenotypes have been reported in enterococci (Table 2) [33,54-56]. They are designated according to the characteristics of the key ligase that encodes either a D-Ala-D-Lac or a D-Ala-D-Ser ligase [36]. In addition to vanA and $v a n B$, the D-Ala-D-Lac ligase group includes vanD and vanM genes. The D-Ala-D-Ser ligase group includes vanC, vanE, vanG, vanL and vanN. The D-Ala-D-Lac-type operons are located on either plasmids or the chromosome; the D-Ala-D-Ser-type operons have been generally detected in the chromosome, except for the case of vanN, which was found in a plasmid in E. faecium [57]. Variable GPA-resistance phenotypes are associated with the presence of different operons, whose expression is inducible (vanA, vanB, van $G$, vanE, vanL, vanM) or constitutive (vanC, vanD, vanN) (Table 2). 
Table 2. Features of GPA resistance in enterococci. PG, peptidoglycan.

\begin{tabular}{|c|c|c|c|c|c|c|c|}
\hline Microorganisms & $\begin{array}{c}\text { GPA } \\
\text { Resistance } \\
\text { Phenotype }\end{array}$ & $\begin{array}{c}\text { Level of } \\
\text { Resistance }\end{array}$ & $\begin{array}{c}\text { MIC }(\mathrm{mg} / \mathrm{L}) \\
\text { of GPAs }\end{array}$ & $\begin{array}{l}\text { Location of } \\
\text { van Genes }\end{array}$ & $\begin{array}{l}\text { Transcription } \\
\text { of van Genes }\end{array}$ & $\begin{array}{c}\text { C-terminal of } \\
\text { Modified PG } \\
\text { Target }\end{array}$ & References \\
\hline $\begin{array}{l}\text { E. faecalis } \\
\text { E. faecium }\end{array}$ & VanA & High & $\begin{array}{l}\text { Vancomycin } 64-100 \\
\text { Teicoplanin } 16-512\end{array}$ & $\begin{array}{c}\text { Plasmid } \\
\text { Chromosome }\end{array}$ & Inducible & D-Ala-D-Lac & [44-46] \\
\hline $\begin{array}{l}\text { E. faecalis } \\
\text { E. faecium }\end{array}$ & VanB & Variable & $\begin{array}{c}\text { Vancomycin 4-1000 } \\
\text { Teicoplanin } 0.5-1 \\
\end{array}$ & $\begin{array}{c}\text { Plasmid } \\
\text { Chromosome }\end{array}$ & Inducible & D-Ala-D-Lac & {$[33,36,44]$} \\
\hline $\begin{array}{c}\text { E. gallinarum } \\
\text { E. casseliflavus } \\
\text { E. flavescens }\end{array}$ & VanC & $\begin{array}{c}\text { Intrinsic resistance, } \\
\text { low level }\end{array}$ & $\begin{array}{l}\text { Vancomycin 2-32 } \\
\text { Teicoplanin } 0.5-1\end{array}$ & Chromosome & Constitutive & D-Ala-D-Ser & {$[33,49,54]$} \\
\hline $\begin{array}{l}\text { E. faecalis } \\
\text { E. faecium }\end{array}$ & VanD & Moderate & $\begin{array}{c}\text { Vancomycin } 64-128 \\
\text { Teicoplanin 4-64 }\end{array}$ & Chromosome & Constitutive & D-Ala-D-Lac & {$[33,53]$} \\
\hline E. faecalis & VanE & Low & $\begin{array}{c}\text { Vancomycin 8-32 } \\
\text { Teicoplanin } 0.5\end{array}$ & Chromosome & Inducible & D-Ala-D-Ser & {$[33]$} \\
\hline $\begin{array}{l}\text { E. faecalis } \\
\text { E. faecium }\end{array}$ & VanG & Low & $\begin{array}{l}\text { Vancomycin } 16 \\
\text { Teicoplanin } 0.5 \\
\end{array}$ & Chromosome & Inducible & D-Ala-D-Ser & [33] \\
\hline E. faecalis & VanL & Low & $\begin{array}{c}\text { Vancomycin } 8 \\
\text { Teicoplanin susceptible }\end{array}$ & Chromosome & Inducible & D-Ala-D-Ser & {$[54]$} \\
\hline E. faecium & VanM & Variable & $\begin{array}{c}\text { Vancomycin }>256 \\
\text { Teicoplanin } 0.75 \\
\end{array}$ & $\begin{array}{c}\text { Plasmid } \\
\text { Chromosome }\end{array}$ & Inducible & D-Ala-D-Lac & {$[56]$} \\
\hline E. faecium & VanN & Low & $\begin{array}{l}\text { Vancomycin } 16 \\
\text { Teicoplanin } 0.5 \\
\end{array}$ & Plasmid & Constitutive & D-Ala-D-Ser & {$[55,57]$} \\
\hline
\end{tabular}


The first case of van gene-mediated resistance in high vancomycin-resistant $S$. aureus (VRSA) was detected in 2002. The VanA phenotype-resistant strain was from a dialysis patient in Michigan co-infected by a vancomycin-resistant $E$. faecalis, implicating horizontal gene transfer mediated by Tn1546 [58,59]. This event was alarming, since $S$. aureus is responsible for severe infections and toxinoses in both the hospital environment and the community, and for almost three decades, vancomycin has been increasingly used to treat $S$. aureus infections, due to the global emergence of MRSA, which is resistant to multiple drug classes [1]. Fortunately, only a few additional VRSA isolates have been reported thus far, including 13 isolates from the United States, 16 from India, 3 from Iran and 1 from Pakistan [60,61], and in no case VRSAs were involved in severe bacteremic infections. Competition growth experiments, in the absence of the inducing vancomycin between MRSA recipient and isogenic VRSA transconjugant, revealed a disadvantage for the transconjugant, accounting, in part, for the low level of dissemination of VRSA clinical isolates [62]. In addition to that, it has been indicated that the restriction modification system of $S$. aureus limits the transfer of resistance genes between isolates of different $S$. aureus lineages [63].

\section{The van Gene Clusters in the Producing Actinomycetes}

GPAs are produced by filamentous actinomycetes, which are soil-dwelling mycelial high G-C content Gram-positive bacteria [64]. Their complex cell life cycle consists of vegetative growth followed by the formation of aerial hyphae and, ultimately, spore formation, the last allowing both dispersal and persistence under unfavorable conditions. The onset of morphological differentiation generally coincides with the production of two-thirds of the commercially-available antibiotics, including GPAs [5,65]. Antibiotic-producing actinomycetes possess mechanisms to avoid suicide by their own toxic products. The extensive review by Cundliffe and Demain [66] covered the different strategies adopted, ranging from target-based ones (i.e., modification of normal drug receptors or de novo synthesis of the latter in the drug-resistant form) to those based on the adoption of molecular shielding and/or efflux that prevent drug-target interactions.

The first evidence that van gene-mediated resistance occurred in the producing actinomycetes dated back to the late 1990s, when orthologues of enterococcal vanHAX were cloned from two GPAs-producing actinomycetes: Streptomyces toyocaensis NRRL15009, which is the producer of the sulfonated sugar-free teicoplanin-like GPA, known as A47934, and the vancomycin producer Amycolatopsis orientalis C329.2 [67]. The predicted amino acid sequences were found to be highly similar to those found in VRE: $54 \%$ to $61 \%$ identity for $\mathrm{VanH}, 59 \%$ to $63 \%$ for VanA and 61 to $64 \%$ identity for VanX $[67,68]$. The D-Ala-D-Ala ligase from $S$. toyocaensis showed D-Ala-D-Lac ligase activity in cell-free extracts of $S$. lividans transformed with the vanA-like gene and confirmed the predicted enzymatic activity [67]. Similar gene sequences were then identified in other GPAs-producers, such as A. orientalis (chloroeremomycin producer), A. orientalis subsp. lurida (ristocetin producer), Amycolatopsis coloradensis subsp. labeda (teicoplanin and avoparcin producer), A. balhimycina (balhimycin producer) and $A$. teichomyceticus (teicoplanin producer), suggesting that actinomycetes may represent the original source of the van genes involved in the synthesis of resistant PG precursors in pathogens [68-71]. 
Sequencing of the A47934 biosynthetic gene cluster (sta) of S. toyocaensis revealed the 5 ' orthologues of the vanHAX cluster organized as a presumptive operon $\left(v a n H_{s t} A_{s t} X_{s t}\right)$, indicating that resistance genes are coupled to the biosynthetic ones in this GPA-producing organism [72]. The co-regulation of resistance and biosynthetic genes involved in A47934 production was confirmed by insertional inactivation of vanAst: the resulting mutant was more susceptible to the GPA, and its production was delayed by 16 hours, until the cells entered into the stationary phase of growth and were no longer sensitive to the GPA action [72]. Associated with $v a n H_{s t} A_{s t} X_{s t}$, the biosynthetic gene cluster sta includes three putative accessory genes (Figure 2): $m u r X_{s t}$, encoding a predicted D-Ala-D-Ala adding enzyme; staO, encoding a protein with high homology to the FemABX family responsible for the production of pentaglycine inter-muramyl chain peptide in the PG [73]; and staP, a putative membrane protein with unclear function (see the paragraph below on Streptomyces coelicolor). vanR $R_{s t}$ and van $S_{s t}$ are not in close proximity to the $v a n H_{s t} A_{s t} X_{s t}$ genes as in VRE and VRSA, but they are separated by approximately 20 $\mathrm{kb}$, outside the $s t a$ biosynthetic cluster [72]. The sensor protein $\mathrm{VanS}_{\mathrm{st}}$ is quite divergent from enterococcal VanS and $\operatorname{VanS}_{\mathrm{B}}$ (15\% overall identity in pairwise comparisons) [48]. Interestingly, S. toyocaensis is resistant to A47934, but it is sensitive to both vancomycin and teicoplanin [74] (Table 3), and it was more recently demonstrated that vancomycin does not trigger $\mathrm{VanS}_{\text {st }}$ autophosphorylation and does not induce GPA resistance in S. toyocaensis [47].

Studies based on the sequencing of fosmid clones or whole genomes have allowed the annotation of van-like genes in other GPAs-producing actinomycetes. Sequencing of the biosynthetic gene cluster for teicoplanin (tcp or tei) of A. teichomyceticus [69,70] revealed the presence at one end of a set of contiguous genes putatively involved in GPA resistance: $m u r F 2$, the vanHAX homologues and two genes codifying for a sensory kinase and a response regulator of a putative two-component signal transduction system (Figure 2). Cloning of these genes in S. coelicolor increased the host GPA resistance, albeit at a reduced level [75]. Notwithstanding the lack of genetic tools for manipulating A. teichomyceticus, Beltrametti et al. [76] demonstrated by quantitative PCR and liquid chromatography-mass spectrometry (LC-MS) of PG precursors that van $H_{a t} A_{a t} X_{a t}$ are organized in an operon, whose expression is constitutive and determines the exclusive production of PG precursors ending in D-Ala-D-Lac depsipeptides. Taking advantage of the high degree of identity (77\%) between the VanS sequences of $S$. coelicolor (see paragraph below) and A. teichomyceticus, two significant amino acid substitutions were identified in the ATPase domain of VanS at, which were considered to be crucial for the VanS phosphorylase activity in S. coelicolor; since their mutation resulted in constitutive van gene expression and subsequent constitutive resistance [77]. As reported in VRE (see the paragraph above), the constitutive resistance phenotype is associated with specific mutations in VanS [52,53]. In A. teichomyceticus, a mutated VanS homolog conferring constitutive GPA resistance may have been selected as an adaptation to teicoplanin production [76]. Consistently, A. teichomyceticus is constitutively resistant to GPAs, with MICs of teicoplanin and vancomycin of 25 and $90 \mu \mathrm{g} / \mathrm{mL}$, respectively (Table 3). 
Table 3. Features of GPA-resistance in actinomycetes.

\begin{tabular}{|c|c|c|c|c|c|c|c|}
\hline Microorganisms & $\begin{array}{c}\text { Produced } \\
\text { GPA }\end{array}$ & $\begin{array}{c}\mathrm{MIC}(\mathrm{mg} / \mathrm{L}) \\
\text { of GPAs } \\
\end{array}$ & $\begin{array}{c}\text { Location of } \\
\text { vanHAX Genes } \\
\end{array}$ & $\begin{array}{c}\text { Transcription of } \\
\text { vanHAX Genes }\end{array}$ & $\begin{array}{c}\text { C-terminal }{ }^{1} \text { of PG Target } \\
\text { in Absence of Inducer }\end{array}$ & $\begin{array}{c}\text { C-terminal }{ }^{1} \text { of PG Target } \\
\text { in Presence of Inducer }\end{array}$ & References \\
\hline $\begin{array}{c}\text { Streptomyces } \\
\text { coelicolor }\end{array}$ & none & $\begin{array}{c}\text { Vancomycin }>100 \\
\text { Teicoplanin }<0.5\end{array}$ & Chromosome & $\begin{array}{l}\text { Inducible by } \\
\text { vancomycin }\end{array}$ & D-Ala-D-Ala & D-Ala-D-Lac & {$[47,78-80]$} \\
\hline $\begin{array}{c}\text { Streptomyces } \\
\text { toyocaensis }\end{array}$ & A47934 & $\begin{array}{c}\text { Vancomycin }<0.25 \\
\text { Teicoplanin }<0.25 \\
\text { A47934 }>5 \\
\end{array}$ & $\begin{array}{l}\text { Chromosome, } \\
\text { A47934 Cluster }\end{array}$ & $\begin{array}{c}\text { Inducible } \\
\text { by A47934 }\end{array}$ & D-Ala-D-Ala & D-Ala-D-Lac & {$[47,68,72,74]$} \\
\hline $\begin{array}{c}\text { Actinoplanes } \\
\text { teichomyceticus }\end{array}$ & Teicoplanin & $\begin{array}{l}\text { Vancomycin } 90 \\
\text { Teicoplanin } 25\end{array}$ & $\begin{array}{c}\text { Chromosome, } \\
\text { tei Cluster }\end{array}$ & Constitutive & D-Ala-D-Lac & D-Ala-D-Lac & {$[69,70,75,76]$} \\
\hline $\begin{array}{c}\text { Amycolatopsis } \\
\text { balhimycin }\end{array}$ & Balhimycin & $\begin{array}{l}\text { Vancomycin n.r. } \\
\text { Teicoplanin n.r. } \\
\text { Balhimycin }>100\end{array}$ & $\begin{array}{l}\text { Chromosome, out } \\
\text { of bal Cluster }\end{array}$ & Constitutive & D-Ala-D-Lac & D-Ala-D-Lac & {$[71]$} \\
\hline $\begin{array}{c}\text { Nonomuraea sp. } \\
\text { ATCC } 39727\end{array}$ & A40926 & $\begin{array}{c}\text { Vancomycin } 30 \\
\text { Teicoplanin } 0.9 \\
\text { A40926 } 4\end{array}$ & n.d. ${ }^{3}$ & $\begin{array}{l}\text { Inducible } \\
\text { by A40926 }\end{array}$ & D-Ala ${ }^{4}$ & D-Ala ${ }^{4}$ & {$[81,82]$} \\
\hline
\end{tabular}

${ }^{1}$ In all of the strains (except Nonomuraea sp. ATCC 39727), the reported C-terminus indicates the terminal dipeptide or the depsipeptide in the pentapeptide stem of the PG precursor; ${ }^{2}$ n.r., not reported. ${ }^{3}$ n.d., not detectable: vanHAX genes have not been found in Nonomuraea sp. ATCC 39727 [80]. ${ }^{4}$ In Nonomuraea sp. ATCC 39727 , the predominant PG precursor is the tetrapeptide UDP-MurNAc-L-Ala-D-Glu-meso-Dap-D-Ala. 
In A. balhimycin, which synthesizes the GPA balhimycin (which differs only in its glycosylation pattern from vancomycin), vanHAX gene homologues were found $2 \mathrm{Mb}$ away from the biosynthetic gene cluster $(b a l)$ [71]. These genes are expressed constitutively, resulting in a constitutive production of PG precursors terminating in D-Ala-D-Lac, as demonstrated by quantitative PCR and LC-MS of PG precursors (Table 3). Within the bal cluster, homologues of known enterococcal resistance genes vanS, $v a n R$ and van $Y$ were initially annotated and named $v n l R$, vnlS and $v a n Y_{b}$. Further studies on the phenotypes of mutated strains showed that the $\mathrm{VnlR} / \mathrm{S}$ two-component system is not involved in GPA resistance: RT-PCR analyses confirmed similar expression levels of $v a n H_{\mathrm{b}} A_{\mathrm{b}} X_{\mathrm{b}}$ and $\operatorname{van}_{\mathrm{b}}$ in the wildtype and in a $v n l R$ deletion mutant [71]. VanY $Y_{b}$ is a D,D-carboxypeptidase, which increases the level of GPA resistance as described in enterococci harboring the vanHAX genes, but in contrast to the enterococcal enzyme, VanYb lacks a predicted membrane association site [71]. Heterologous expression of VanY $Y_{b}$ in $S$. coelicolor increased the level of balhimycin resistance in the host $(50 \mu \mathrm{g} / \mathrm{mL}$ versus $10 \mu \mathrm{g} / \mathrm{mL}$ in an agar diffusion test). In contrast, the expression of Van $\mathrm{Y}_{\mathrm{b}}$ in the $\Delta v a n R / S$ mutant of $S$. coelicolor [83], which is susceptible to vancomycin (since the vanHAX genes cannot be induced due to the absence of the two-component regulatory system; see the paragraph below), did not confer balhimycin resistance in this background. These data indicate that $\operatorname{van}_{b}$ is an accessory gene that requires functional VanHAX proteins to increase the level of resistance [71].

More recently, the sequence assembly s from metagenomic samples [10-12] has allowed the identification of the following GPA clusters: VEG (vancomycin-like environmental DNA-derived gene cluster), TEG (teicoplanin-like environmental DNA-derived gene cluster), CA37, CA878, CA915 and two teicoplanin-type molecules with eSNaPD (environmental Surveyor of Natural Product Diversity) identification numbers 15 and 26 [10-12]. In these environmental clusters, the position of genes that encode each class of enzyme required for the biosynthesis of a GPA is conserved: interestingly, resistance genes (vanHAX-like) are grouped together at the beginning of the cluster, followed by nonribosomal peptide synthetase genes [11].

\section{The Model System Streptomyces Coelicolor}

S. coelicolor is genetically the model species of antibiotic-producing filamentous actinomycetes [84]. It harbors a vanHAX gene cluster, but it does not produce any GPA [78,84]. S. coelicolor lives in soil and shares the same ecological niche with GPA-producing actinomycetes; thus, it seems likely that it might have acquired van genes, gaining a selective advantage [77]. The genetic cluster consists of seven genes (vanRSJKHAX) divided into four transcription units (vanRS, vanJ, vanK and vanHAX) that confer high inducible resistance to vancomycin, but not to teicoplanin (the VanB enterococcal phenotype) (Figure 2, Table 3). The predicted products of the $S$. coelicolor vanH, vanA and vanX genes are close homologues (ranging from $60 \%$ to $65 \%$ ) of their counterparts from VRE [78] and, when switched on, reprogram PG biosynthesis replacing D-Ala-D-Ala terminating PG precursors in D-Ala-D-Lac-ending ones [83].

VanS and VanR proteins of $S$. coelicolor are indeed quite divergent from their enterococcal equivalents [78]. VanS of $S$. coelicolor shows a high homology (65\%-77\% overall identity in pairwise comparisons) with equivalent sensor proteins in S. toyocaensis and in A. teichomyceticus [47], and its function has been intensively studied $[47,77,80]$. The $\Delta v a n R / S$ mutant of $S$. coelicolor is susceptible to 
vancomycin, since this GPA cannot induce vanHAX genes, due to the absence of the two-component regulatory system [77,78]. Studying a set of $S$. coelicolor mutants, the following model of the two-component regulation of GPA resistance was proposed: on exposure to vancomycin, VanS's activity switches from being a phosphatase to a kinase, and the resulting accumulation of phospho-VanR activates transcription from van promoters and induces vancomycin resistance. In the absence of drug, however, the constitutive phosphorylation of the response regulator VanR mediated by small-molecule phosphor-donor acetyl phosphate is suppressed by the phosphatase activity of VanS [77]. Koteva et al. [47] showed that a vancomycin phoaffinity probe binds to $S$. coelicolor $\operatorname{VanS}$ and that binding is required for the expression of the van genes and for resistance to vancomycin, suggesting that for at least some VanS sensor kinases associated with the VanB phenotype, the antibiotic itself is the ligand that induces drug resistance. More recently, Kwun et al. [80] undertook a series of in vivo experiments, which indicate that $S$. coelicolor VanS is activated by vancomycin in complex with the D-Ala-D-Ala termini of PG precursors. This may represent a new intermediate model between the alternative ones previously proposed, i.e., the direct binding of the antibiotic to the sensor domain or the indirect induction by intermediate cell wall metabolites accumulating as a result of antibiotic action. The two accessory genes, vanJ and vanK, were not found in VRE [78,79]. VanJ is a membrane protein that increases resistance to teicoplanin in S. coelicolor, but is not required for resistance to vancomycin [79]. Interestingly, VanJ is orthologous to $S$. toyocaensis StaP (75\% amino acid sequence identity), previously identified in the A47934 biosynthetic cluster. A thorough comprehension of VanJ function in the cell wall metabolism needs further elucidation, which might be relevant to obtaining a more complete understanding of the mode of action of teicoplanin (Table 2) [81].

The vanK gene is indeed essential for vancomycin resistance: it is a member of the Fem proteins family, which add the glycine/s to the stem pentapeptide of PG precursors [78]. In S. coelicolor, the branch is a single glycine residue, and in the absence of vancomycin, this residue is added by the FemX enzyme. However, the constitutive FemX activity in $S$. coelicolor can recognize only PG precursors terminating in D-Ala-D-Ala as a substrate [83]. VanK is required for vancomycin resistance, because it is the only enzyme that can add glycine to PG precursors terminating in D-Ala-D-Lac. Production of precursors lacking a side-chain would be lethal, because this would prevent cross-linking of the PG by transpeptidase, leading to cell lysis [83]. VanK enzyme is important for GPA resistance, not just in S. coelicolor, since an orthologous $(s t a O)$ was previously identified in the A47934 biosynthetic cluster [72]. In contrast, the absence of orthologues of vanK in vancomycin-resistant clusters of pathogens implies that their FemX can recognize precursors terminating in D-Ala-D-Ala or D-Ala-D-Lac.

\section{The Case of Nonomuraea sp. ATCC 39727}

The Nonomuraea sp. ATCC 39727 produces the teicoplanin-like A40926 that is the precursor of the semi-synthetic dalbavancin [26,28]. Homologues of vanHAX genes were not found by sequencing the A40926 biosynthetic gene cluster $(d b v)$ [85]. They were not also identified by mining Nonomuraea genome by southern hybridization using degenerate primers and vanHat $A_{a t} X_{a t}$ genes from $A$. teichomyceticus as probes [81]. Moreover, preliminary data from genome sequencing of Nonomuraea sp. ATCC 39727 indicated a lack of significant homology with van genes from A. teichomyceticus and enterococci [81]. 
Nonomuraea sp. ATCC 39727 shows a moderate resistance to GPAs (Table 3); interestingly, A40926 MIC is $4 \mu \mathrm{g} / \mathrm{mL}$ during vegetative growth, but this increases to $c a .20 \mu \mathrm{g} / \mathrm{mL}$ during A40926 production, suggesting the induction of an alternative mechanism of self-protection. Thus far, the sole resistant determinant identified in Nonomuraea sp. is the vanY-like gene ( $v a n Y_{\mathrm{n}}$ ) found in the $d b v$ cluster and encoding a zinc-dependent D,D-carboxypeptidase capable of removing the terminal D-Ala residue of pentapeptide in the PG precursors, leaving tetrapeptide that is not recognized by GPAs [81]. Accordingly, analysis of PG precursors by LC-MS revealed the predominant presence of the tetrapeptide UDP-MurNAc-L-Ala-D-Glu-meso-Dap-D-Ala and only traces of the corresponding pentapeptide terminating in D-Ala-D-Ala [79]. Consistently, a van $Y_{n}$ null mutant of Nonomuraea sp. demonstrated a reduced level of GPA resistance and accumulated the pentapeptide PG precursors, and its complementation restored resistance and the cell wall phenotype [81,82]. Recently, Hugonnet et al. [86] reported that the PG of Nonomuraea sp. ATCC 39727 was partially cross-linked by an L,D-transpeptidase (LTD) that uses the tetrapeptide acyl donors supplied by the Van $Y_{n}$ action on the pentapeptide PG precursors. In many bacteria, especially among Actinomycetales, LTDs catalyze the formation of $3 \rightarrow 3$ linkages, complementing the action of the better known D,D-transpeptidases of the penicillin binding protein (PBP) family that use precursors containing a pentapeptide stem and catalyze the formation of $4 \rightarrow 3$ cross-links connecting the fourth amino acid residue of the acyl donor to the third position of the acyl acceptor. In Nonomuraea sp. ATCC 39727 during exponential growth, 49\% of the cross-links were generated by L,D-transpeptidation, whereas in the stationary phase, the proportion of $3 \rightarrow 3$ cross-links was lower (31\%) [86].

Recombinant Van $Y_{n}$ was heterologously expressed in and purified from either S. venezuelae or Escherichia coli [87,88]. It is a membrane-bound bi-functional D,D-peptidase and D,D-carboxypeptidase, containing conserved motifs ( $\mathrm{SxHxxGxAxD}$ and ExxH) involved in the coordination of zinc and in the active site that are typical of VanY and VanX zinc-dependent D,D-carboxypeptidases and D,D-peptidases characterized in GPA-resistant enterococci $[38,39,41,89]$. The dual function of VanY $Y_{n}$ most closely resembles the one of $\mathrm{VanXY}_{\mathrm{C}}$ from VanC-type Enterococcus gallinarum, which combines the specificity of VanX and VanY as it hydrolyzes both the D-Ala-D-Ala and the PG precursor analogs ending in D-Ala [90]. Surprisingly, increasing concentrations of penicillin G and ampicillin inhibited VanY $Y_{n}$ activity, whereas zinc-dependent VanX peptidases and VanY carboxypeptidases from enterococci are resistant to $\beta$-lactams [39,89]. In enterococci, both zinc-dependent D,D-carboxypeptidases and low molecular weight penicillin binding proteins (LMW PBPs) catalyze the same reaction, but have a completely different protein domain architecture [91]. Similar to classical VanY enzymes, Van $Y_{n}$ lacks the canonical Ser-x-x-Lys motif found in the active sites of PBPs; thus, how $\beta$-lactams inhibit Van $Y_{n}$ activity is worthy of further investigations. Despite the high identity of the conserved sequences belonging to the active sites, the overall identity between Van $Y_{n}$ and the previously described VanY and VanX enzymes in enterococci is moderate, ranging from $25 \%$ to $46 \%$ [87]. Van $Y_{n}$ shows $48 \%$ sequence identity with $V_{a n} Y_{b}$ D,D-carboxypeptidase identified in the bal cluster of A. balhimycina [71], but it differs from Van $Y_{\mathrm{b}}$ in the mass and cellular localization [82,87]. In the recent work by Meziane-Cherif et al. [92], the phylogenetic reconstruction of the metallo peptidase M15 family showed that Van $Y_{n}$ is close to, but does not branch within, the group of VanY (including Van $Y_{b}$ ) and VanXY from enterococci (subfamily M15B). This suggests that Van $Y_{n}$ can represent an ancestral enzyme with a role in self-resistance, then recruited for resistance in other bacteria through structural changes that affect 
its substrate specificity and activity. Other authors taking advantage of the tools developed to genetically manipulate Nonomuraea sp. [93,94], recently varying van $Y_{n}$ gene dosage and expressing vanHat $A_{a t} X_{a t}$ from the teicoplanin producer A. teichomyceticus in Nonomuraea sp. Knocking out, complementing a $\operatorname{van}_{n}$ mutant or duplicating $\operatorname{van}_{n}$ influenced antibiotic resistance, confirming the role of this gene in conferring moderate resistance to GPAs in Nonomuraea sp. due to the incomplete conversion of the PG pentapeptide precursors to the tetrapeptides. Heterologous expression of vanHat $A_{a t} X_{a t}$ increased A40926 resistance in Nonomuraea sp. and resulted in the marked accumulation of the UDP-MurNAc-pentadepsipeptide (terminating in D-Lac) [82].

Figure 2. Comparison of resistance gene organization in enterococci (VanA, VanB and VanC phenotypes) in Streptomyces coelicolor and in GPAs-producers. Two parallel vertical lines indicate that genes that are not present in contiguous regions (figure modified from Yim et al. [2]).

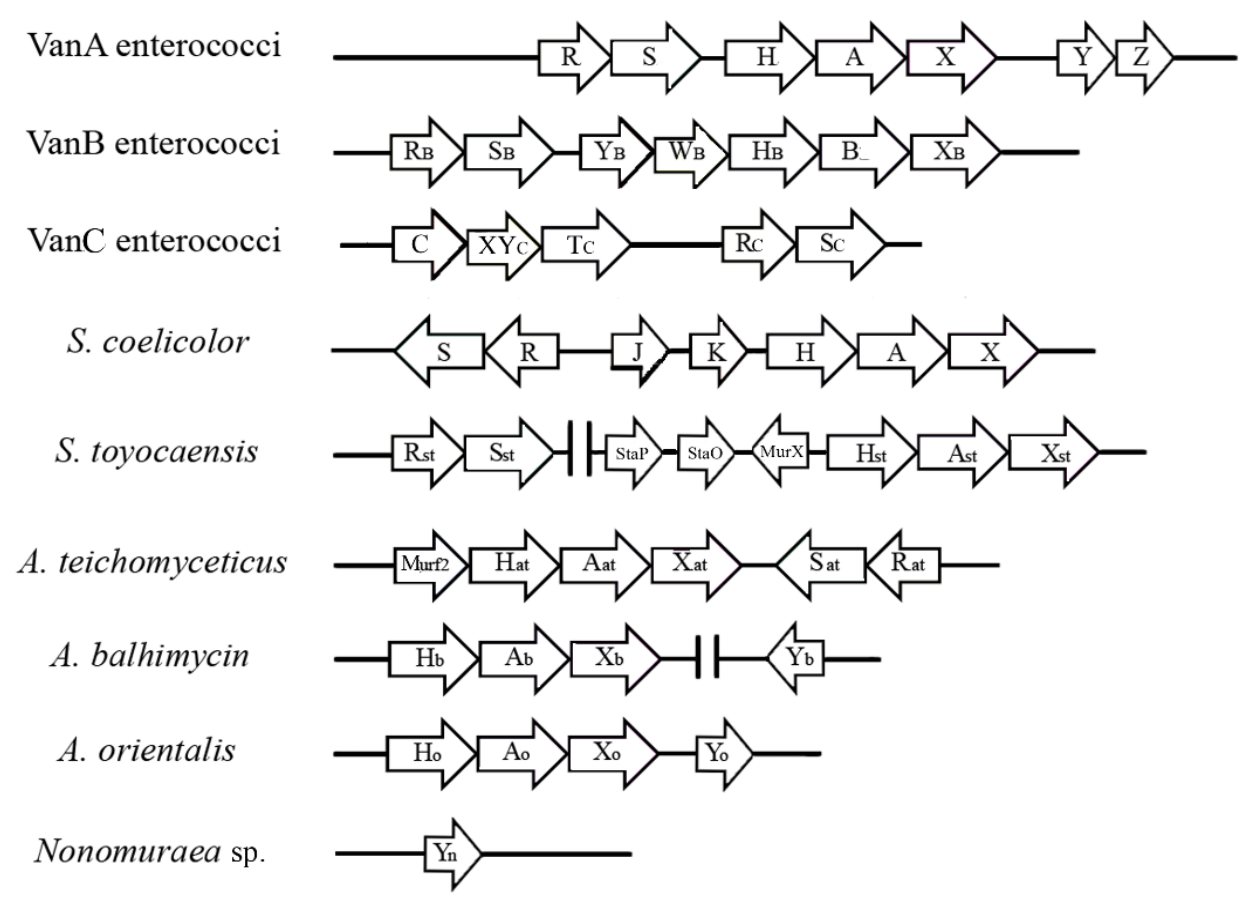

\section{Conclusions}

The core vanHAX genes have been detected in all of the published GPAs-producers (except the A40926 producer). The last announcement comes from the genome sequencing of $A$. orientalis that produces vancomycin: in this case, vanHAX is located in the front of the vancomycin biosynthetic genes [95]. In addition, vanHAX have been recently found in GPA-like gene clusters identified in environmental DNA by metagenomics tools [2,10-12]. In most of the reported cases (except the balhimycin producer), vanHAX is part of, or very close to, the GPAs-biosynthetic cluster, suggesting a coordinated regulation of GPA production and resistance. As reported in the case of A. balhimycina and A. teichomyceticus, these producers bypass the VanRS regulation, and the vanHAX genes are constitutively expressed. This might be a safety mechanism to protect nonproducing cells living in a population with neighboring GPA producer cells, during the critical transition from the growth phase towards antibiotic production. Interestingly, in a recent work based on the resistance-guided isolation of 
novel GPA-producing actinomycetes, Thaker et al. identified two distinct Streptomyces sp. strains (WAC1420 and WAC4229) that produce a novel GPA, named pekiskomycin [96]. Their draft genomes show identical biosynthetic cluster organization, except for recombinations in WAC4229, resulting in the loss of vanRS. Thus, it appears that among GPA producers, the lack of vanRS-based regulation may be a quite common feature. In contrast, stringent regulation of resistance gene expression represents a more common trait of not-producing bacteria, such as $S$. coelicolor, and resistant pathogens that remodel their cell wall biosynthesis only if exposed to GPAs. The ubiquitous presence of regulatory systems in these bacteria indicates that there is a selective advantage for the production of alternate types of precursors in response to environmental conditions.

In enterococci, staphylococci and actinomycetes, vanHAX are always present in the same order and are co-transcribed, and the VanHAX proteins show high levels of amino acid sequence identity across different resistant genotypes. Regulatory genes may be placed upstream or downstream of the vanHAX genes in enterococci or far away in the genome of actinomycetes. The lack of sequence similarity in the sensor domains of VanS kinases reflects different modes of recognition of GPAs. Most gene clusters include accessory resistance genes that are specific for each cluster and whose function is generally less known. van $Y$ are considered ancillary genes in enterococci, but apparently, they are relevant resistance determinants in some GPA-producing actinomycetes. In enterococci, they are much more diverse than VanHAX, and their genes occupy different positions in different resistant genotypes, i.e., upstream or downstream of vanHAX. Some GPA-producing actinomycetes possess, alternatively, vanHAX or van $Y$ genes, and some others combine vanHAX and vanY. Since, in VRE, levels of resistance to GPAs are determined by the extent of elimination of PG precursors ending in D-Ala-D-Ala, vanHAX and vanY combination perhaps emerged and was selected in actinomycetes and pathogens as the most protective solution, whereby VanX and VanY enzymes act in sequence to eliminate PG precursors ending with D-Ala-D-Ala.

Concluding, several lines of evidence indicate that van gene clusters have been generated by the recruitment of different genes or sets of genes from the GPA-producing actinomycetes, including the variations in the guanosine plus cytosine content in different portions of the cluster, the variable percentage of sequence identity between the encoded proteins, the variation in the order of genes and the contribution of unrelated accessory proteins. Studying resistance determinants in the actinomycetes may provide new insights into their evolution and may also contribute to an early warning system for emerging resistance mechanisms due to the exposure to old and new GPAs. This may also provide new targets to design specific inhibitors to be used in combination with GPAs.

\section{Acknowledgments}

This work was supported by grants from Fondo di Ateneo per la Ricerca to F. Marinelli, by Progetto Cariplo: Promuovere Capitale Umano d'Eccellenza to G. L. Marcone and E. Binda, by the MIUR (Ministero dell'Istruzione, dell'Università e della Ricerca) fellowship to G. L. Marcone and by Consorzio Interuniversitario Biotecnologie fellowships to G. L. Marcone and E. Binda. 


\section{Author Contributions}

E. Binda collected data and papers and co-wrote the review; F. Marinelli supervised the work and co-wrote the review; G. L. Marcone prepared the figures and co-wrote the review.

\section{Conflicts of Interest}

The authors declare no conflict of interest.

\section{References}

1. Rossolini, G.M.; Arena, F.; Pollini, S. Novel infectious diseases and emerging gram-positive multiresistant pathogens in hospital and community acquired infections. In Antimicrobials; Marinelli, F., Genilloud, O., Eds.; Springer Verlag: Berlin Heidelberg, Germany, 2014.

2. Yim, G.; Thaker, M.N.; Koteva, K.; Wright, G. Glycopeptide antibiotic biosynthesis. J. Antibiot. (Tokyo) 2014, 67, 31-41.

3. Kahne, D.; Leimkuhler, C.; Lu, W.; Walsh, C. Glycopeptide and lipoglycopeptide antibiotics. Chem. Rev. 2005, 105, 425-448.

4. Jovetic, S.; Zhu, Y.; Marcone, G.L.; Marinelli, F.; Tramper, J. $\beta$-Lactam and glycopeptide antibiotics: First and last line of defense? Trends Biotechnol. 2010, 28, 596-604.

5. Marcone, G.L.; Marinelli, F. Glycopeptides: An old but up to date successful antibiotic class. In Antimicrobials; Marinelli, F., Genilloud, O., Eds.; Springer Verlag: Berlin Heidelberg, Germany, 2014.

6. James, R.C.; Pierce, J.G.; Okano, A.; Xie, J.; Boger, D.L. Redesign of glycopeptide antibiotics: Back to the future. ACS Chem. Biol. 2012, 7, 797-804.

7. Nicolaou, K.C.; Boddy, C.N.; Bräse, S.; Winssinger, N. Chemistry, biology, and medicine of the glycopeptide antibiotics. Angew. Chem. Int. Ed. Engl. 1999, 38, 2096-2152.

8. Thaker, M.N.; Wright, G.D. Opportunities for synthetic biology in antibiotics: Expanding glycopeptide chemical diversity. ACS Synth. Biol. 2012, doi:10.1021/sb300092n.

9. Kalan, L.; Perry, J.; Koteva, K.; Thaker, M.; Wright, G. Glycopeptide sulfation evades resistance. J. Bacteriol. 2013, 195, 167-171.

10. Banik, J.J.; Brady, S.F. Cloning and characterization of new glycopeptide gene clusters found in an environmental DNA megalibrary. Proc. Natl. Acad. Sci. USA 2008, 105, 17273-17277.

11. Banik, J.J.; Brady, S.F. Recent application of metagenomic approaches toward the discovery of antimicrobials and other bioactive small molecules. Curr. Opin. Microbiol. 2010, 13, 603-609.

12. Owen, J.G.; Reddy, B.V.; Ternei, M.A.; Charlop-Powers, Z.; Calle, P.Y.; Kim, J.H.; Brady, S.F. Mapping gene clusters within arrayed metagenomic libraries to expand the structural diversity of biomedically relevant natural products. Proc. Natl. Acad. Sci. USA 2013, 110, 11797-11802.

13. Borghi, A.; Edwards, D.; Zerilli, L.F.; Lancini, G.C. Factors affecting the normal and branched-chain acyl moieties of teicoplanin components produced by Actinoplanes teichomyceticus. J. Gen. Microbiol. 1991, 137, 587-592.

14. Taurino, C.; Frattini, L.; Marcone, G.L.; Gastaldo, L.; Marinelli, F. Actinoplanes teichomyceticus ATCC 31121 as a cell factory for producing teicoplanin. Microb. Cell Fact. 2011, 10, e82. 
15. Cooper, M.A.; Williams, D.H. Binding of glycopeptide antibiotics to a model of a vancomycinresistant bacterium. Chem. Biol. 1999, 6, 891-899.

16. Van Bambeke, F. Glycopeptides and glycodepsipeptides in clinical development: A comparative review of their antibacterial spectrum, pharmacokinetics and clinical efficacy. Curr. Opin. Investig. Drugs 2006, 7, 740-749.

17. Jeya, M.; Moon, H.J.; Lee, K.M.; Kim, I.W.; Lee, J.K. Glycopeptide antibiotics and their novel semi-synthetic derivatives. Curr. Pharm. Biotechnol. 2011, 12, 1194-1204.

18. Cynamon, M.H.; Granato, P.A. Comparison of the in vitro activities of teichomycin A2 and vancomycin against staphylococci and enterococci. Antimicrob. Agents Chemother. 1982, 21, 504-505.

19. Mackay, J.P.; Gerhard, U.; Beauregard, D.A.; Westwell, M.S.; Searle, M.S.; Williams, D.H. Glycopeptide antibiotic activity and the possible role of dimerization: A model for biological signaling. J. Am. Chem. Soc. 1994, 116, 4581-4590.

20. Ashford, P.A.; Bew, S.P. Recent advances in the synthesis of new glycopeptide antibiotics. Chem. Soc. Rev. 2012, 41, 957-978.

21. Zhanel, G.G.; Calic, D.; Schweizer, F.; Zelenitsky, S.; Adam, H.; Lagacé-Wiens, P.R.; Rubinstein, E.; Gin, A.S.; Hoban, D.J.; Karlowsky, J.A. New lipoglycopeptides: A comparative review of dalbavancin, oritavancin and telavancin. Drugs 2010, 70, 859-886.

22. Higgins, D.L.; Chang, R.; Debabov, D.V.; Leung, J.; Wu, T.; Krause, K.M.; Sandvik, E.; Hubbard, J.M.; Kaniga, K.; Schmidt, D.E.; et al. Telavancin, a multifunctional lipoglycopeptide, disrupts both cell wall synthesis and cell membrane integrity in methicillin-resistant Staphylococcus aureus. Antimicrob. Agents Chemother. 2005, 49, 1127-1134.

23. U.S. Food and Drug Administration. Available online: http://www.fda.gov/ (accessed on 23 October 2014).

24. Bouza, E.; Burillo, A. Oritavancin: A novel lipoglycopeptide active against gram-positive pathogens including multiresistant strains. Int. J. Antimicrob. Agents 2010, 36, 401-407.

25. Belley, A.; McKay, G.A.; Arhin, F.F.; Sarmiento, I.; Beaulieu, S.; Fadhil, I.; Parr, T.R.; Moeck, G. Oritavancin disrupts membrane integrity of Staphylococcus aureus and vancomycin-resistant enterococci to effect rapid bacterial killing. Antimicrob. Agents Chemother. 2010, 54, 5369-5371.

26. Goldstein, B.P.; Selva, E.; Gastaldo, L.; Berti, M.; Pallanza, R.; Ripamonti, F.; Ferrari, P.; Denaro, M.; Arioli, V.; Cassani, G. A40926, a new glycopeptide antibiotic with anti-Neisseria activity. Antimicrob. Agents Chemother. 1987, 31, 1961-1966.

27. Malabarba, A.; Ciabatti, R. Glycopeptide derivatives. Curr. Med. Chem. 2001, 8, 1759-1773.

28. Malabarba, A.; Goldstein, B.P. Origin, structure, and activity in vitro and in vivo of dalbavancin. J. Antimicrob. Chemother. 2005, 55, 15-20.

29. Billeter, M.; Zervos, M.J.; Chen, A.Y.; Dalovisio, J.R.; Kurukularatne, C. Dalbavancin: A novel once-weekly lipoglycopeptide antibiotic. Clin. Infect. Dis. 2008, 46, 577-583.

30. Treviño, J.; Bayón, C.; Ardá, A.; Marinelli, F.; Gandolfi, R.; Molinari, F.; Jimenez-Barbero, J.; Hernáiz, M.J. New insights into glycopeptide antibiotic binding to cell wall precursors using SPR and NMR spectroscopy. Chemistry 2014, 20, 7363-7372.

31. Derlot, R.; Duval, E.J.; Courvalin, P. Plasmid-mediated resistance to vancomycin and teicoplanin in Enterococcus faecium. N. Engl. J. Med. 1988, 319, 157-161. 
32. Arias, C.A.; Murray, B.E. The rise of the enterococcus: Beyond vancomycin resistance. Nat. Rev. Microbiol. 2012, 10, 266-278.

33. Courvalin, P. Vancomycin resistance in gram-positive cocci. Clin. Infect. Dis. 2006, 42, S25-S34.

34. Bugg, T.D.; Wright, G.D.; Dutka-Malen, S.; Arthur, M.; Courvalin, P.; Walsh, C.T. Molecular basis for vancomycin resistance in Enterococcus faecium BM4147: Biosynthesis of a depsipeptide peptidoglycan precursor by vancomycin resistance proteins VanH and VanA. Biochemistry 1991, 30, 10408-10415.

35. Lessard, I.A.; Healy, V.L.; Park, I.S.; Walsh, C.T. Determinants for differential effects on D-ala-D-lactate $v s$. D-ala-D-ala formation by the VanA ligase from vancomycin-resistant enterococci. Biochemistry 1999, 38, 14006-14022.

36. Arthur, M.; Reynolds, P.; Courvalin, P. Glycopeptide resistance in enterococci. Trends Microbiol. 1996, 4, 401-407.

37. Arthur, M.; Molinas, C.; Bugg, T.D.; Wright, G.D.; Walsh, C.T.; Courvalin, P. Evidence for in vivo incorporation of D-lactate into peptidoglycan precursors of vancomycin-resistant enterococci. Antimicrob. Agents Chemother. 1992, 36, 867-869.

38. Reynolds, P.E.; Depardieu, F.; Dutka-Malen, S.; Arthur, M.; Courvalin, P. Glycopeptide resistance mediated by enterococcal transposon Tn1546 requires production of VanX for hydrolysis of D-alanyl-D-alanine. Mol. Microbiol. 1994, 13, 1065-1070.

39. Wu, Z.; Wright, G.D.; Walsh, C.T. Overexpression, purification, and characterization of VanX, a D,D-dipeptidase which is essential for vancomycin resistance in Enterococcus faecium BM4147. Biochemistry 1995, 34, 2455-2463.

40. Arthur, M.; Depardieu, F.; Molinas, C.; Reynolds, P.; Courvalin, P. The vanZ gene of Tn1546 from Enterococcus faecium BM4147 confers resistance to teicoplanin. Gene 1995, 154, 87-92.

41. Arthur, M.; Depardieu, F.; Cabanié, L.; Reynolds, P.; Courvalin, P. Requirement of the VanY and VanX D,D-peptidases for glycopeptide resistance in enterococci. Mol. Microbiol. 1998, 30, 819-830.

42. Arthur, M.; Depardieu, F.; Gerbaud, G.; Galimand, M.; Leclercq, R.; Courvalin, P. The VanS sensor negatively controls VanR-mediated transcriptional activation of glycopeptide resistance genes of Tn1546 and related elements in the absence of induction. J. Bacteriol. 1997, 179, 97-106.

43. Arthur, M.; Depardieu, F.; Courvalin, P. Regulated interactions between partner and non-partner sensors and response regulators that control glycopeptide resistance gene expression in enterococci. Microbiology 1999, 145, 1849-1858.

44. Arthur, M.; Quintiliani, R. Regulation of VanA- and VanB-type glycopeptide resistance in enterococci. Antimicrob. Agents Chemother. 2001, 45, 375-381.

45. Wright, G.D.; Holman, T.R.; Walsh, C.T. Purification and characterization of VanR and the cytosolic domain of VanS: A two-component regulatory system required for vancomycin resistance in Enterococcus faecium BM4147. Biochemistry 1993, 32, 5057-5063.

46. Healy, V.L.; Lessard, I.A.; Roper, D.I.; Knox, J.R.; Walsh, C.T. Vancomycin resistance in enterococci: Reprogramming of the D-ala-D-ala ligases in bacterial peptidoglycan biosynthesis. Chem. Biol. 2000, 7, R109-R119. 
47. Koteva, K.; Hong, H.J.; Wang, X.D.; Nazi, I.; Hughes, D.; Naldrett, M.J.; Buttner, M.J.; Wright, G.D. A vancomycin photoprobe identifies the histidine kinase VanSsc as a vancomycin receptor. Nat. Chem. Biol. 2010, 6, 327-329.

48. Hong, H.J.; Hutchings, M.I.; Buttner, M.J.; Biotechnology and Biological Sciences Research Council, U.K. Vancomycin resistance VanS/VanR two-component systems. Adv. Exp. Med. Biol. 2008, 631, 200-213.

49. Depardieu, F.; Podglajen, I.; Leclercq, R.; Collatz, E.; Courvalin, P. Modes and modulations of antibiotic resistance gene expression. Clin. Microbiol. Rev. 2007, 20, 79-114.

50. Billot-Klein, D.; Blanot, D.; Gutmann, L.; van Heijenoort, J. Association constants for the binding of vancomycin and teicoplanin to $\mathrm{N}$-acetyl-D-alanyl-D-alanine and $\mathrm{N}$-acetyl-D-alanyl-D-serine. Biochem. J. 1994, 304, 1021-1022.

51. Reynolds, P.E.; Courvalin, P. Vancomycin resistance in enterococci due to synthesis of precursors terminating in D-alanyl-D-serine. Antimicrob. Agents Chemother. 2005, 49, 21-25.

52. Baptista, M.; Depardieu, F.; Reynolds, P.; Courvalin, P.; Arthur, M. Mutations leading to increased levels of resistance to glycopeptide antibiotics in VanB-type enterococci. Mol. Microbiol. 1997, 25, 93-105.

53. Depardieu, F.; Kolbert, M.; Pruul, H.; Bell, J.; Courvalin, P. VanD-type vancomycin-resistant Enterococcus faecium and Enterococcus faecalis. Antimicrob. Agents Chemother. 2004, 48, 3892-3904.

54. Boyd, D.A.; Willey, B.M.; Fawcett, D.; Gillani, N.; Mulvey, M.R. Molecular characterization of Enterococcus faecalis N06-0364 with low-level vancomycin resistance harboring a novel D-ala-D-ser gene cluster, VanL. Antimicrob. Agents Chemother. 2008, 52, 2667-2672.

55. Lebreton, F.; Depardieu, F.; Bourdon, N.; Fines-Guyon, M.; Berger, P.; Camiade, S.; Leclercq, R.; Courvalin, P.; Cattoir, V. D-Ala-D-ser VanN-type transferable vancomycin resistance in Enterococcus faecium. Antimicrob. Agents Chemother. 2011, 55, 4606-4612.

56. Xu, X.; Lin, D.; Yan, G.; Ye, X.; Wu, S.; Guo, Y.; Zhu, D.; Hu, F.; Zhang, Y.; Wang, F.; et al. VanM, a new glycopeptide resistance gene cluster found in Enterococcus faecium. Antimicrob. Agents Chemother. 2010, 54, 4643-4647.

57. Nomura, T.; Tanimoto, K.; Shibayama, K.; Arakawa, Y.; Fujimoto, S.; Ike, Y.; Tomita, H. Identification of VanN-type vancomycin resistance in an Enterococcus faecium isolate from chicken meat in Japan. Antimicrob. Agents Chemother. 2012, 56, 6389-6392.

58. Bartley, J. First case of VRSA identified in Michigan. Infect. Control Hosp. Epidemiol. 2002, 23,480 .

59. Weigel, L.M.; Clewell, D.B.; Gill, S.R.; Clark, N.C.; McDougal, L.K.; Flannagan, S.E.; Kolonay, J.F.; Shetty, J.; Killgore, G.E.; Tenover, F.C. Genetic analysis of a high-level vancomycin-resistant isolate of Staphylococcus aureus. Science 2003, 302, 1569-1571.

60. Moravvej, Z.; Estaji, F.; Askari, E.; Solhjou, K.; Naderi Nasab, M.; Saadat, S. Update on the global number of vancomycin-resistant Staphylococcus aureus (VRSA) strains. Int. J. Antimicrob. Agents 2013, 42, 370-371.

61. Rossi, F.; Diaz, L.; Wollam, A.; Panesso, D.; Zhou, Y.; Rincon, S.; Narechania, A.; Xing, G.; di Gioia, T.S.; Doi, A.; et al. Transferable vancomycin resistance in a community-associated MRSA lineage. N. Engl. J. Med. 2014, 370, 1524-1531. 
62. Foucault, M.L.; Courvalin, P.; Grillot-Courvalin, C. Fitness cost of VanA-type vancomycin resistance in methicillin-resistant Staphylococcus aureus. Antimicrob. Agents Chemother. 2009, 53, 2354-2359.

63. Périchon, B.; Courvalin, P. VanA-type vancomycin-resistant Staphylococcus aureus. Antimicrob. Agents Chemother. 2009, 53, 4580-4587.

64. Marinelli, F. Chapter 2. From microbial products to novel drugs that target a multitude of disease indications. Methods Enzymol. 2009, 458, 29-58.

65. Marinelli, F.; Marcone, G. Small molecules, microbial secondary metabolites. In Comprehensive Biotechnology, 2nd ed.; Moo-Young, M., Ed.; Elsevier: Amsterdam, The Netherlands, 2011; Volume 3, pp. 285-297.

66. Cundliffe, E.; Demain, A.L. Avoidance of suicide in antibiotic-producing microbes. J. Ind. Microbiol. Biotechnol. 2010, 37, 643-672.

67. Marshall, C.G.; Broadhead, G.; Leskiw, B.K.; Wright, G.D. D-Ala-D-Ala ligases from glycopeptide antibiotic-producing organisms are highly homologous to the enterococcal vancomycin-resistance ligases VanA and VanB. Proc. Natl. Acad. Sci. USA 1997, 94, 6480-6483.

68. Marshall, C.G.; Lessard, I.A.; Park, I.; Wright, G.D. Glycopeptide antibiotic resistance genes in glycopeptide-producing organisms. Antimicrob. Agents Chemother. 1998, 42, 2215-2220.

69. Sosio, M.; Kloosterman, H.; Bianchi, A.; de Vreugd, P.; Dijkhuizen, L.; Donadio, S. Organization of the teicoplanin gene cluster in Actinoplanes teichomyceticus. Microbiology 2004, 150, 95-102.

70. Li, T.L.; Huang, F.; Haydock, S.F.; Mironenko, T.; Leadlay, P.F.; Spencer, J.B. Biosynthetic gene cluster of the glycopeptide antibiotic teicoplanin: Characterization of two glycosyltransferases and the key acyltransferase. Chem. Biol. 2004, 11, 107-119.

71. Schäberle, T.F.; Vollmer, W.; Frasch, H.J.; Hüttel, S.; Kulik, A.; Röttgen, M.; von Thaler, A.K.; Wohlleben, W.; Stegmann, E. Self-resistance and cell wall composition in the glycopeptide producer Amycolatopsis balhimycina. Antimicrob. Agents Chemother. 2011, 55, 4283-4289.

72. Pootoolal, J.; Thomas, M.G.; Marshall, C.G.; Neu, J.M.; Hubbard, B.K.; Walsh, C.T.; Wright, G.D. Assembling the glycopeptide antibiotic scaffold: The biosynthesis of A47934 from Streptomyces toyocaensis NRRL15009. Proc. Natl. Acad. Sci. USA 2002, 99, 8962-8967.

73. Hegde, S.S.; Shrader, T.E. Femabx family members are novel nonribosomal peptidyltransferases and important pathogen-specific drug targets. J. Biol. Chem. 2001, 276, 6998-7003.

74. Neu, J.M.; Wright, G.D. Inhibition of sporulation, glycopeptide antibiotic production and resistance in Streptomyces toyocaensis NRRL15009 by protein kinase inhibitors. FEMS Microbiol. Lett. 2001, 199, 15-20.

75. Serina, S.; Radice, F.; Maffioli, S.; Donadio, S.; Sosio, M. Glycopeptide resistance determinants from the teicoplanin producer Actinoplanes teichomyceticus. FEMS Microbiol. Lett. 2004, 240, 69-74.

76. Beltrametti, F.; Consolandi, A.; Carrano, L.; Bagatin, F.; Rossi, R.; Leoni, L.; Zennaro, E.; Selva, E.; Marinelli, F. Resistance to glycopeptide antibiotics in the teicoplanin producer is mediated by van gene homologue expression directing the synthesis of a modified cell wall peptidoglycan. Antimicrob. Agents Chemother. 2007, 51, 1135-1141.

77. Hutchings, M.I.; Hong, H.J.; Buttner, M.J. The vancomycin resistance VanRS two-component signal transduction system of Streptomyces coelicolor. Mol. Microbiol. 2006, 59, 923-935. 
78. Hong, H.J.; Hutchings, M.I.; Neu, J.M.; Wright, G.D.; Paget, M.S.; Buttner, M.J. Characterization of an inducible vancomycin resistance system in Streptomyces coelicolor reveals a novel gene (vanK) required for drug resistance. Mol. Microbiol. 2004, 52, 1107-1121.

79. Novotna, G.; Hill, C.; Vincent, K.; Liu, C.; Hong, H.J. A novel membrane protein, VanJ, conferring resistance to teicoplanin. Antimicrob. Agents Chemother. 2012, 56, 1784-1796.

80. Kwun, M.J.; Novotna, G.; Hesketh, A.R.; Hill, L.; Hong, H.J. In vivo studies suggest that induction of VanS-dependent vancomycin resistance requires binding of the drug to D-Ala-D-Ala termini in the peptidoglycan cell wall. Antimicrob. Agents Chemother. 2013, 57, 4470-4480.

81. Marcone, G.L.; Beltrametti, F.; Binda, E.; Carrano, L.; Foulston, L.; Hesketh, A.; Bibb, M.; Marinelli, F. Novel mechanism of glycopeptide resistance in the A40926 producer Nonomuraea sp. ATCC 39727. Antimicrob. Agents Chemother. 2010, 54, 2465-2472.

82. Marcone, G.L.; Binda, E.; Carrano, L.; Bibb, M.; Marinelli, F. The relationship between glycopeptide production and resistance in the actinomycete Nonomuraea sp. ATCC 39727. Antimicrob. Agents Chemother. 2014, 58, doi:10.1128/AAC.02626-14.

83. Hong, H.J.; Hutchings, M.I.; Hill, L.M.; Buttner, M.J. The role of the novel Fem protein VanK in vancomycin resistance in Streptomyces coelicolor. J. Biol. Chem. 2005, 280, 13055-13061.

84. Bentley, S.D.; Chater, K.F.; Cerdeño-Tárraga, A.M.; Challis, G.L.; Thomson, N.R.; James, K.D.; Harris, D.E.; Quail, M.A.; Kieser, H.; Harper, D.; et al. Complete genome sequence of the model actinomycete Streptomyces coelicolor A3(2). Nature 2002, 417, 141-147.

85. Sosio, M.; Stinchi, S.; Beltrametti, F.; Lazzarini, A.; Donadio, S. The gene cluster for the biosynthesis of the glycopeptide antibiotic A40926 by Nonomuraea species. Chem. Biol. 2003, 10, 541-549.

86. Hugonnet, J.E.; Haddache, N.; Veckerlé, C.; Dubost, L.; Marie, A.; Shikura, N.; Mainardi, J.L.; Rice, L.B.; Arthur, M. Peptidoglycan cross-linking in glycopeptide-resistant actinomycetales. Antimicrob. Agents Chemother. 2014, 58, 1749-1756.

87. Binda, E.; Marcone, G.L.; Pollegioni, L.; Marinelli, F. Characterization of VanY(n), a novel D,D-peptidase/D,D-carboxypeptidase involved in glycopeptide antibiotic resistance in Nonomuraea sp. ATCC 39727. FEBS J. 2012, 279, 3203-3213.

88. Binda, E.; Marcone, G.L.; Berini, F.; Pollegioni, L.; Marinelli, F. Streptomyces spp. as efficient expression system for a D,D-peptidase/D,D-carboxypeptidase involved in glycopeptide antibiotic resistance. BMC Biotechnol. 2013, 13, e24.

89. Wright, G.D.; Molinas, C.; Arthur, M.; Courvalin, P.; Walsh, C.T. Characterization of VanY, a D,D-carboxypeptidase from vancomycin-resistant Enterococcus faecium BM4147. Antimicrob. Agents Chemother. 1992, 36, 1514-1518.

90. Reynolds, P.E.; Arias, C.A.; Courvalin, P. Gene vanxyc encodes D,D-dipeptidase (VanX) and D,D-carboxypeptidase (VanY) activities in vancomycin-resistant Enterococcus gallinarum BM4174. Mol. Microbiol. 1999, 34, 341-349.

91. Mainardi, J.L.; Villet, R.; Bugg, T.D.; Mayer, C.; Arthur, M. Evolution of peptidoglycan biosynthesis under the selective pressure of antibiotics in gram-positive bacteria. FEMS Microbiol. Rev. 2008, 32, 386-408.

92. Meziane-Cherif, D.; Stogios, P.J.; Evdokimova, E.; Savchenko, A.; Courvalin, P. Structural basis for the evolution of vancomycin resistance D,D-peptidases. Proc. Natl. Acad. Sci. USA 2014, 111, $5872-5877$. 
93. Marcone, G.L.; Carrano, L.; Marinelli, F.; Beltrametti, F. Protoplast preparation and reversion to the normal filamentous growth in antibiotic-producing uncommon actinomycetes. J. Antibiot. (Tokyo) 2010, 63, 83-88.

94. Marcone, G.L.; Foulston, L.; Binda, E.; Marinelli, F.; Bibb, M.; Beltrametti, F. Methods for the genetic manipulation of Nonomuraea sp. ATCC 39727. J. Ind. Microbiol. Biotechnol. 2010, 37 , 1097-1103.

95. Jeong, H.; Sim, Y.M.; Kim, H.J.; Lee, D.W.; Lim, S.K.; Lee, S.J. Genome sequence of the vancomycin-producing Amycolatopsis orientalis subsp. Orientalis strain KCTC 9412T. Genome Announc. 2013, 1, doi:10.1128/genomeA.00408-13.

96. Thaker, M.N.; Wang, W.; Spanogiannopoulos, P.; Waglechner, N.; King, A.M.; Medina, R.; Wright, G.D. Identifying producers of antibacterial compounds by screening for antibiotic resistance. Nat. Biotechnol. 2013, 31, 922-927.

(C) 2014 by the authors; licensee MDPI, Basel, Switzerland. This article is an open access article distributed under the terms and conditions of the Creative Commons Attribution license (http://creativecommons.org/licenses/by/4.0/). 